\title{
EXPERIMENTAL STUDY OF CLINICAL VITAMIN B DEFICIENCY ${ }^{1}$
}

\author{
By KATHARINE O'SHEA ELSOM \\ (From the Gastro-Intestinal Section of the Medical Clinic, Hospital of the University of Penn- \\ sylvania, and the John Herr Musser Department of Research Medicine, \\ University of Pennsylvania, Philadelphia)
}

(Received for publication August 27, 1934)

Clinical disturbances incident to mild deficiency of vitamin $\mathrm{B}^{2}$ in the diet, as opposed to frank deficiencies such as beriberi and pellagra, are commonly believed to be very rare in man and are thought to occur only when the diet is grossly abnormal or when there is serious interference with absorption from the gastro-intestinal tract. Certain observations made in this Gastro-Intestinal Section, however, have suggested that clinical evidences of such partial deficiency may develop on given for the first five months a diet moderately deficient in vitamin $B$ though adequate in every other known requirement and the effects of this diet were studied. When clinical signs suggestive of deficiency were manifest, various vitamin B fractions were added to the diet, in series, and the effects of their administration studied. The second patient (Case 2), who entered the hospital with fully developed clinical evidence of deficiency, was likewise placed on a diet restricted in

TABLE I

Chart showing articles composing the diet deficient in the vitamin $B$ complex

Cereals

Cream of wheat

Rice

White cornmeal

Fruit

Orange juice: 100 grams daily

Apple

Pear

Grape

Cocoanut

Fats

Butter

Cod liver oil: 10 grams daily

Lard

a diet which is not obviously abnormal and in the absence of serious gastro-intestinal disease. Experiments to test this hypothesis were carried out on two patients, one of whom (Case 1) was hospitalized for approximately a year. She was

1 Aided by a grant from the Faculty Research Committee of the University of Pennsylvania.

2 The term vitamin B as used in this paper includes all members of the vitamin $B$ complex; individual members are referred to as $B_{1}, B_{2}(G)$, and the "additional factors ": $B_{4}, B_{s}$, and factor $Y$.

Pie: apple

\section{Pastry and desserts}

$\left.\begin{array}{l}\text { Raisin pudding } \\ \text { Cornstarch pudding }\end{array}\right\}$ without milk

Jello

Cake ${ }^{\text {pear }}$ with white flour

Biscuits $\}$ and without milk or egg

Jelly: grape apple
Vegetables

Potatoes: white

Turnips

Corn

Spinach

Onion

Beets

Cabbage

Rutabaga

Carrots

Boiled 2 hours
Bevera
Tea
Coffee

\begin{abstract}
Seasonings as desired Chocolate, cinnamon, molasses, salt, etc.
\end{abstract}

its content of vitamin B and was studied during the addition to it of separate vitamin $B$ fractions.

\section{METHODS OF STUDY}

The articles of which the experimental diet was composed are recorded in Table $I .^{3}$

8 The vitamin $B_{1}$ content of the diet for Case 1 was calculated by Dr. George Cowgill according to a formula of his as yet unpublished, and was found to contain approximately one-half of the theoretical vitamin $B_{1}$ requirement. 
All food was weighed. Caloric, fluid and protein intake was constant throughout the entire experiment, the latter intake amounting to 49 grams per day for Case 1, and 68 grams for Case 2. Daily output of urine was measured. Symptoms and physical signs were recorded daily. Mouth temperature was taken morning and evening. The patients were weighed daily under standard conditions on a balance accurate to within 8 grams. Nitrogen balance was determined during 2 three-day periods, both food and excreta being analyzed. Roentgen examination of the gastrointestinal tract was made at the beginning and end of each experimental period; observations of the level and tone of the stomach, of the type of peristalsis, and of the motility throughout the small intestine and colon were made every two hours for six hours. Fractional gastric analyses were carried out using oatmeal gruel as the test meal. Exercise tolerance tests (1) were performed during each experimental period. Blood pressure and pulse rate were measured under basal conditions and repeated on standing and after climbing 54 steps at maximal speed. Serum protein analyses, enumeration of red blood cells, hemoglobin estimations (2) and hematocrit readings, carried out under conditions which insured complete packing of cells, were made weekly. Venous pressure was measured from accessible veins on the dorsum of the hand by the indirect method of Krogh, Turner and Landis (3). Determination of capillary permeability was made in Case 1 at the height of the edema using the procedures described by Landis, Jonas, Angevine and Erb (4). Respiratory quotient, basal metabolic rate, electrocardiograms, orthodiagrams, tests of renal function, platelet counts, sugar tolerance tests and estimations of coagulation time were made in the routine hospital laboratories.

The vitamin $B_{1}$ substance ${ }^{4}$ was prepared as an 80 per cent alcoholic extract of wheat embryo according to the method of Bourquin and Sherman (5). Using the rat growth method of biological assay (6), this extract was found to be free of other vitamin fractions and to be potent in vita$\min B_{1}, 1 \mathrm{cc}$. of the extract containing approxi-

4 Vitamin materials were prepared and assayed in the Laboratory of Physiological Chemistry under the direction of Dr. J. H. Jones, to whom acknowledgement is gratefully made. mately 21 Sherman units. The required dose of this substance for Case 1, 11.3 cc., was calculated from the optimal dose in rats on the basis of relative caloric requirements. To be certain of adequate dosage $20 \mathrm{cc}$. were given daily for 3 weeks, after which the daily dose was increased to $40 \mathrm{cc}$. The vitamin $\mathrm{B}_{2}$ concentrate was made from egg white by the method of Chick, Copping and Roscoe (7). It was found to be potent in vitamin $B_{2}$ and free of other vitamin fractions. The calculated human dose was first doubled, 60 cc. of the extract being given daily for 2 weeks, and then increased to $120 \mathrm{cc}$. for the remainder of the experiment. Powdered brewer's yeast concentrate $^{5}$ prepared by a modification of the Osborne and Wakeman method (8) and known to contain factors in addition to vitamins $B_{1}$ and $B_{2}$ necessary for maximal growth in the rat (Figure 2) was used as a source of additional B factors. An arbitrary dose of 6 tablespoonfuls was given daily. An extract of rice polishings suitable for parenteral use, ${ }^{6}$ shown (9) to be a potent source of vitamin $B_{1}$ was used for a short time in Case 2; the daily dose employed varied from 2 to $4 \mathrm{cc}$.

\section{PROTOCOL}

Case 1. A woman, 56 years old, $158 \mathrm{~cm}$. tall, weighing 57.2 kilos, had been admitted one year prior to hospitalization as an out-patient to this Section, complaining of anorexia, sore tongue, asthenia, paresthesias in the lower extremities, dyspnea and vertigo. She at that time gave a history of voluntary restriction of diet for 10 years and, as described elsewhere (10), had a bald tongue, exaggerated patellar reflexes, impaired vibratory sensation and edema of the lower extremities. Blood studies and gastric analysis were negative. Whole yeast concentrate was administered at that time for 6 weeks, following which the patient had become symptom free and was then without physical signs except exaggerated reflexes and diminished vibratory sensation in the lower extremities. She had continued in good health throughout the remainder of that year. It was then decided to determine the effect of moderate limitation of diet at home. This was done for 6 weeks prior to hospitalization with the result that on admission some impairment of appetite, slight intermittent edema of the ankles, and occasional sore tongue were manifest. The strict experimental diet was begun immediately upon admission,

5 Obtained from the Harris Laboratories, Tuckahoe, New York.

6 This material was kindly supplied through the courtesy of Dr. A. W. Rhodehamel of the Eli Lilly Research Laboratories. 
May 17, 1933, and was continued until March 29, 1934. For a period of 21 days in August 1933 she was away from the hospital but continued the diet. The times at which the various vitamin fractions were added to the diet together with various other data from the case may be seen in Figure 1. ently been taking an adequate diet in addition to considerable quantities of beer, but had induced vomiting several times weekly to relieve abdominal distress. Constipation persisted, and dyspnea, vertigo, palpitation and edema had developed. Cardiac and renal studies were negative. Free hydrochloric acid was obtained from the

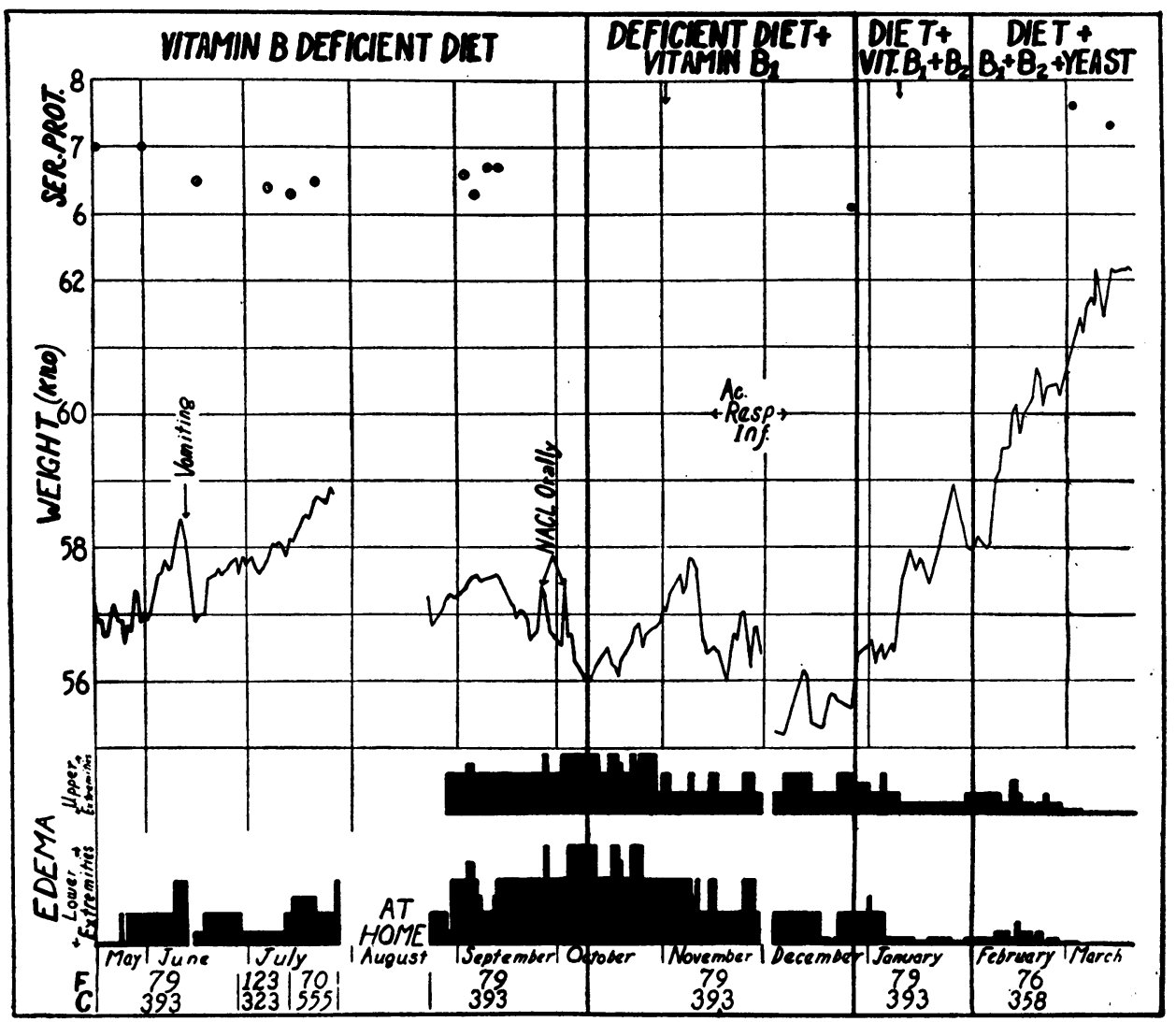

Fig. 1. Case 1. Changes in Weight, Edema and Serum Protein on Vitamin B Deficient Diet and Following Administration of Vitamin B Fractions.

Arrows at the top of the chart indicate doubled dosage of vitamin $B_{1}$ and $B_{2}$ preparations respectively. Daily intake of fat and carbohydrate in grams is recorded at the bottom of the chart.

Case 2. A man aged 53 years, weighing 65.1 kilos at the beginning of observation, had had a long history prior to this admission. In 1924, when first seen in the hospital, he complained of epigastric discomfort after eating, and of nausea, vomiting and constipation. Roentgenological study at that time revealed extensive gastric polyposis and repeated examinations subsequently showed no change. Gastric analysis, routine blood examinations and all other laboratory studies were negative in 1924 . In 1927 the symptoms had not changed, except that epigastric distress had become sufficiently severe to cause the patient to induce vomiting. All studies were negative except those of the blood, which showed red cells numbering 3,450,000 and hemoglobin of 85 per cent. In 1930 the patient again entered the hospital. He had appar- stomach only after histamine. Peripheral reflexes were exaggerated. Red blood cells numbered $3,000,000$; the hemoglobin was 64 per cent. On November 13, 1933, he was again admitted to the hospital because of alternate attacks of constipation and diarrhea, the latter persisting several weeks at a time, with 10 or more movements daily. His appetite was good, although his dietary habits, the induced vomiting, and the epigastric discomfort were unchanged. Dyspnea, palpitation and vertigo had increased. He complained of being easily fatigued. The tongue was smooth and red. Edema extended to the knees. Tests of renal function and orthodiagram were negative. An electrocardiogram showed moderate tachycardia. Blood pressure was 102/68. He complained of "crawling sensations" in the feet and legs. Reflexes 
were exaggerated and vibratory sensation greatly impaired in the lower extremities. Other neurological findings were normal. Gastric acid was present in moderate amounts without histamine. Red blood cell count was $3,700,000$ with hemoglobin of 75 per cent. Serum protein was 4.97 grams per $100 \mathrm{cc}$. blood. Blood sugar determinations and glucose tolerance tests gave normal figures. He remained on the regular ward routine for 19 days, during which time no change occurred in symptomatology, physical signs or laboratory findings. Following this period the experimental observations were begun (see Figure 6). Diarrhea, induced by sulphates used in preparation of the egg white extract, made it necessary to discontinue the administration of that substance. Yeast therapy was begun immediately and the patient was therefore not observed on vitamin $B_{1}$ and $B_{2}$ therapy alone. The $B_{2}$ content of the yeast was supplemented by 5 eggs daily. Believing that there might be interference with absorption from the gastro-intestinal tract the vitamin $\mathrm{B}_{\mathbf{1}}$ preparation for parenteral use described above was given intravenously. After 7 weeks on the experimental régime he left the hospital, continuing the diet and vitamin therapy. He returned 3 times weekly for observation and intravenous administration of the vitamin $B_{1}$ preparation.

\section{RESULTS}

Case 1. The symptoms and physical signs which developed in the course of the experiment are outlined in Table II. All of the findings listed in the period " deficient diet" had developed within the first 5 weeks of that period, after which there was a gradual increase in their severity. During the period of deficient diet plus administration of vitamin $B_{1}$ improvement was first observed 2 weeks after therapy was begun. Midway in this period the patient developed an acute upper respiratory infection accompanied by fever. All manifestations of deficiency became aggravated in spite of increased dosage of the vitamin preparation. After subsidence of the infection the improvement noted during the first 2 weeks returned. Attention is directed to the fact that improvement during administration of vitamin $B_{1}$ and of vitamin $B_{1}$ and $B_{2}$ was not continued in certain respects during the end of the latter period and was resumed only when yeast was added to the diet. It is to be noted, also, that symptoms of anorexia and epigastric distress were relieved only when therapy with yeast was begun.

Data relating to body weight, edema and serum protein are presented in Figure 1. It is worthy of note that during the period of vitamin deficiency the body weight decreased while the edema increased, whereas during the periods of vitamin administration increase of weight was accompanied by a disappearance of edema. Serum protein remained above the critical level for edema throughout the entire experiment, but an increase was observed during full vitamin therapy. Nitro-

TABLE II

Symptoms and physical signs present in Case 1 at the conclusion of each experimental period

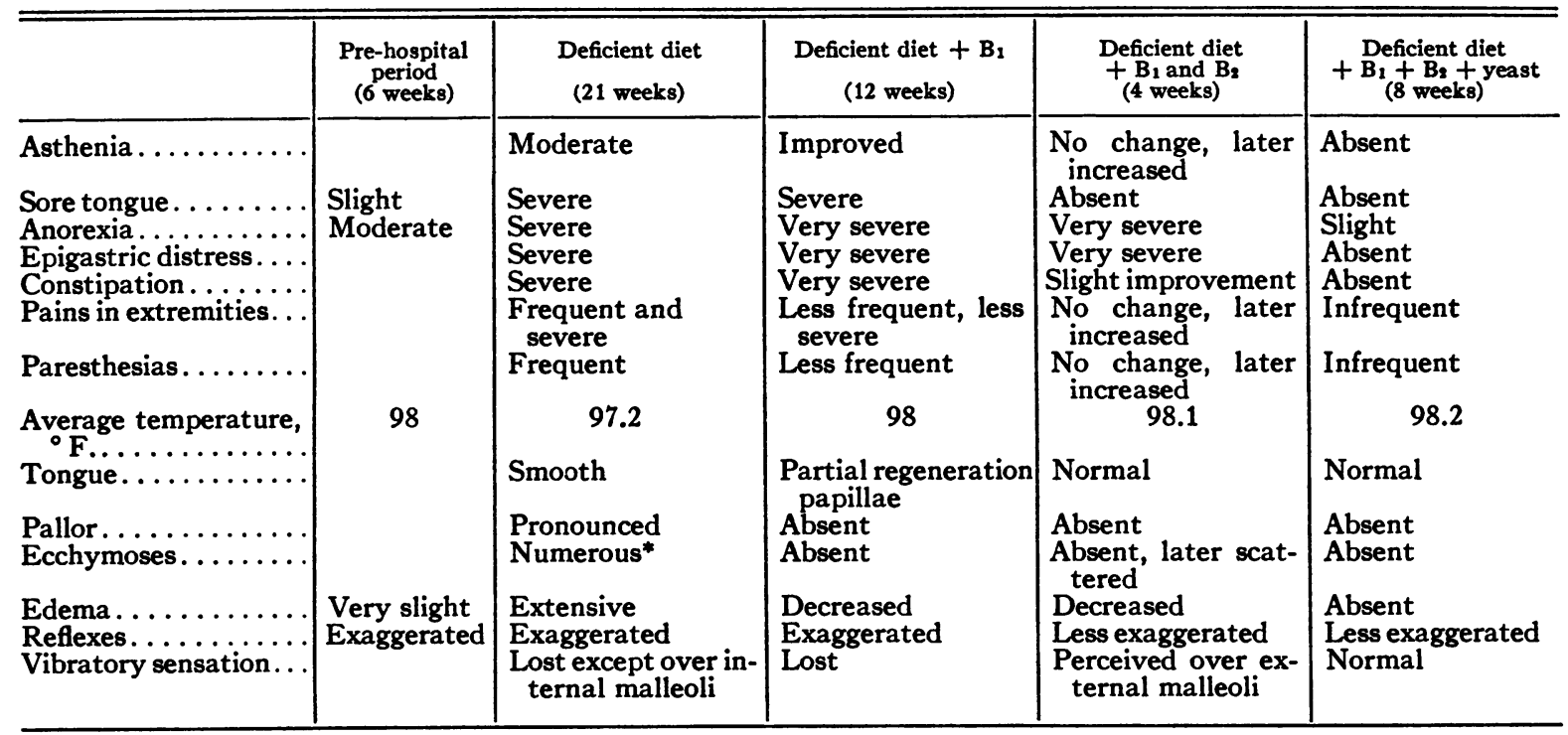

* Ecchymoses varied from 1 to $2 \mathrm{~cm}$. in diameter; they were distributed over forearms and legs. 
gen balance was found positive when vitamin $B_{1}$ was added to the deficient diet. The striking gain in weight observed when the deficient diet and vitamin $B_{1}$ and $B_{2}$ preparations were supplemented by yeast was duplicated in rats rendered vitamin B deficient on a Sherman basal diet (5) and to which the same preparations were fed in -analogous dosage (see Figure 2).
Red blood cell enumeration, hemoglobin and hematocrit readings made throughout the entire experiment are shown in Figure 3. Platelet counts were normal, as was bleeding time. Clotting time, determined on 2 occasions during deficiency, averaged 13 minutes; at the end of vitamin therapy it was 7 minutes.

Blood pressure changes following standard ex-

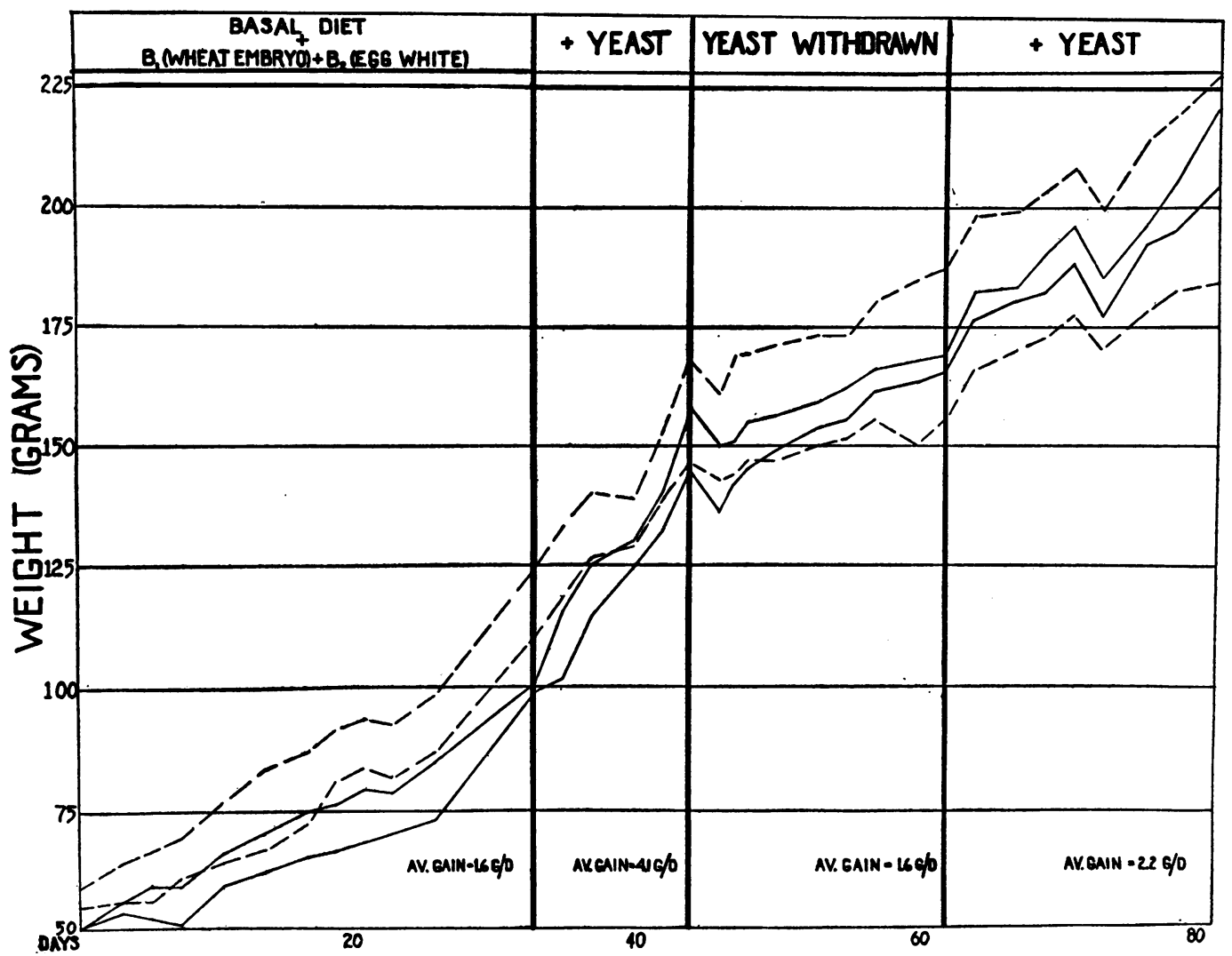

Fig. 2. Weight Curves of Rats Receiving a Sherman Basal Diet free of Vitamin B Supplemented by Wheat Embryo, Egg White and Yeast.

Broken lines indicate growth of animals receiving doubled dosage of egg white.

Venous pressure in Case 1 was between 7 and $10 \mathrm{~cm}$. of water. Measurements of the volume of fluid lost through the capillary wall were made at venous pressure of $67 \mathrm{~mm}$. mercury and the protein content of this fluid calculated. The average calculated volume of fluid filtered in 6 experiments was $10.5 \mathrm{cc}$. per $100 \mathrm{cc}$. blood. The average amount of protein in this filtrate was 1.5 gram per $100 \mathrm{cc}$. These results fall within the normal limits observed by Landis et al. (4), hence they provide no evidence of increased capillary permeability. ercise are shown in Figure 4. Preliminary control readings showed a variation of $5 \mathrm{~mm}$. mercury under the standard conditions of the test. The difference in blood pressure before and after vitamin therapy is most clearly seen in the reading obtained after exercise. Systolic pressure at the end of the deficient period fell 10 minutes after exercise to $88 \mathrm{~mm}$. mercury but after vitamin therapy it fell only to $130 \mathrm{~mm}$. mercury.

Electrocardiogram, orthodiagram and tests of renal function were negative.

The results of roentgen examination of the 
gastro-intestinal tract are recorded diagrammatically in Figure 5. Gastric atony is represented by failure of the stomach to support the column of barium well into the fundus. This was noted marked increase of motility in the small intestine; at the end of two hours there was only a small gastric residue, the head of the meal had reached the cecum, the majority of it being in the ileum;

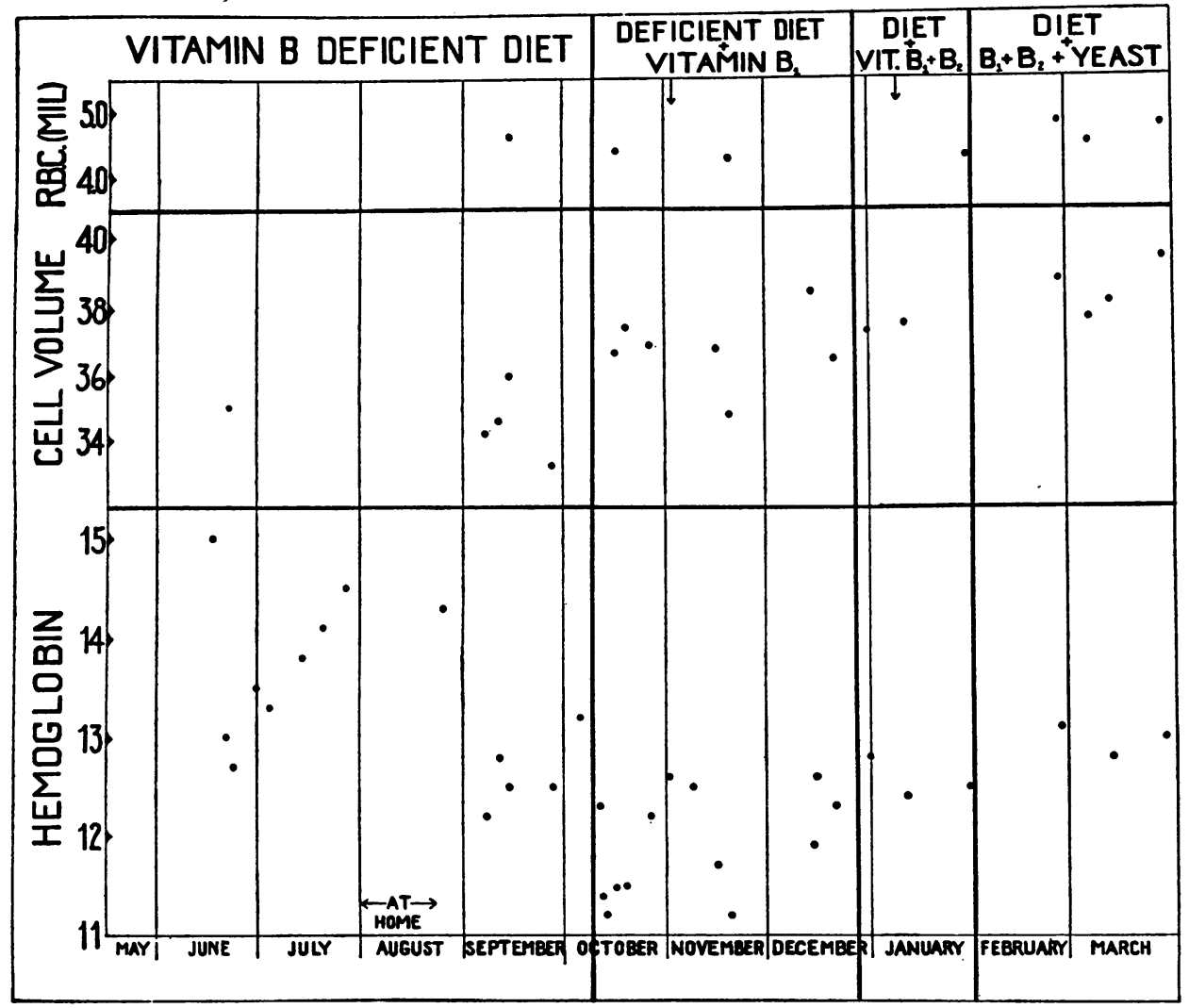

Fig. 3. Case 1. Changes in Hemoglobin, Cell Volume and Number of Red Blood Cells on Vitamin B Deficient Diet and Following Administration of Vitamin B Fractions.

Arrows at the top of the chart indicate doubled dosage of vitamin $B_{1}$ and $B_{2}$ preparations respectively.

in increasing extent until after the conclusion of the administration of vitamin $B_{1}$ and $B_{2}$. Throughout these periods peristalsis was infrequent, and the waves were shallow; at the end of two hours over one-half the meal still remained in the stomach; stasis in the small intestine was evident six hours after giving the barium meal. After yeast therapy there was distinct improvement in gastric tone; the stomach was more globular in shape and supported the column of barium well into the fundus; peristalsis was active and produced prompt emptying of the stomach; ten minutes after giving the barium meal considerable material had passed into the duodenum and had progressed well into the jejunum; there was a colonic motility was increased, the meal having advanced to the splenic flexure at the end of four hours. These changes in the gastro-intestinal tract seen by fluoroscope took place at the time that the patient noticed relief from epigastric distress, a return of appetite and relief from constipation.

Gastric analysis at the end of the deficient period gave normal values for acid.

Blood sugar on two occasions during deficiency averaged $83 \mathrm{mgm}$. per $100 \mathrm{cc}$. blood. Glucose tolerance test gave normal figures. Respiratory quotient, determined with the patient at rest, was 0.77 and 0.78 . After 11 days on a high carbohydrate diet the quotient was 0.88 . At the end 
of combined vitamin therapy it was 0.72. Basal metabolic rate was normal throughout the entire experiment.
4 kilos on addition of yeast to the diet, on the other hand, has been maintained. Anemia did not improve during the control period (see Fig-

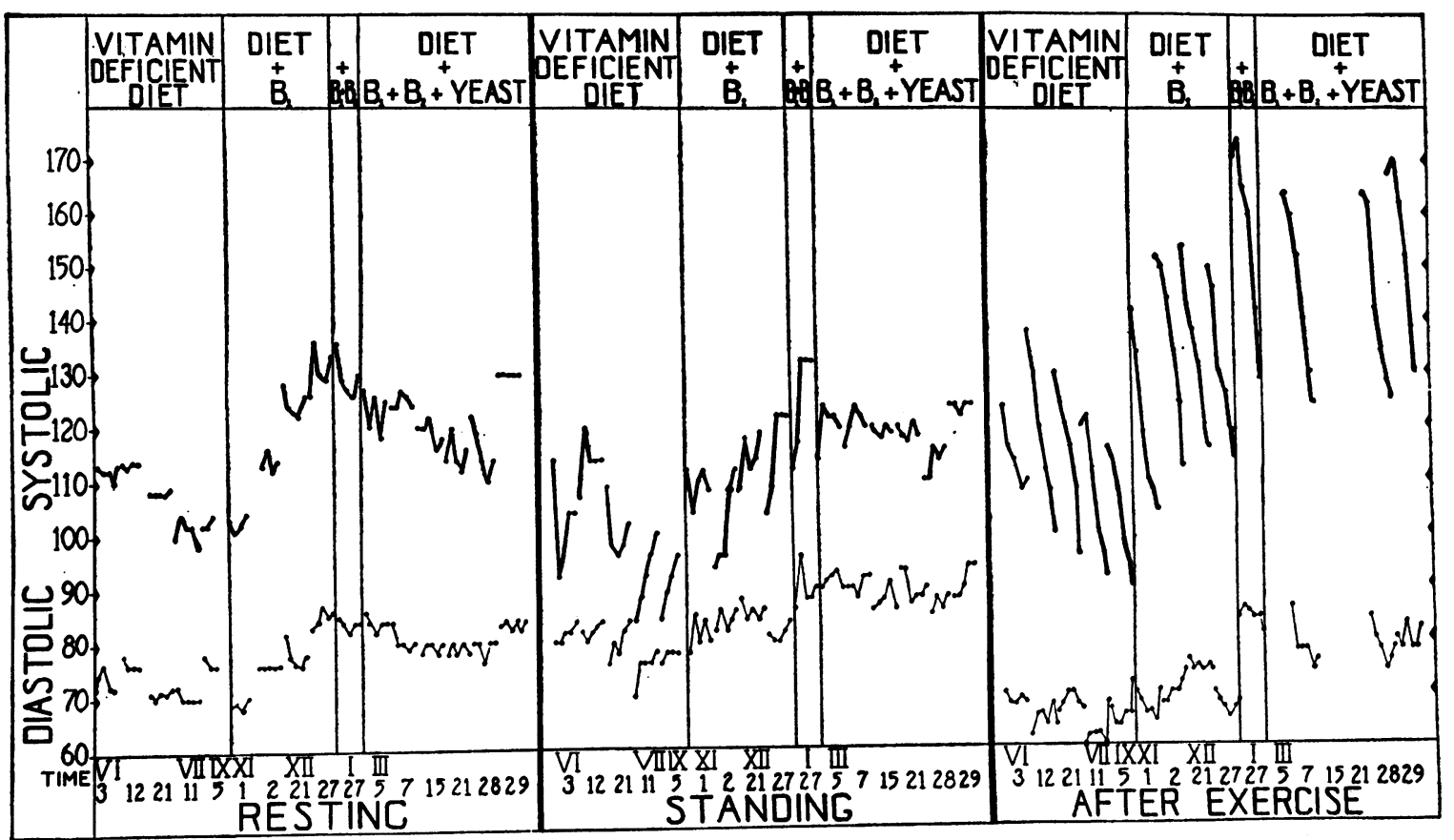

Fig. 4. Case 1. Variations in Diastolic and Systolic Bloon Pressure, While at Rest, After Assuming a Standing Position, and After Rapid Ascent up 54 Steps, While on the Vitamin B Deficient Diet, and During the Administration of Vitamin B Fractions.

Each point in a continuous line represents successive readings at 1 minute intervals for 5 minutes. An additional reading was made at the end of 10 minutes after exercise.

Case 2. In Figure 6A are shown the results of observations of serum protein, weight, and edema. Total serum protein at the end of the control period was 4.46 grams per $100 \mathrm{cc}$. blood. Colloid osmotic pressure of the serum calculated according to the formula of Govaerts (11) (12) was $16.2 \mathrm{~mm}$. mercury. When edema first decreased the total protein was 5.17 grams per 100 cc. blood, and when edema was negligible $\mathbf{5 . 5 0}$ grams per $100 \mathrm{cc}$. blood. The calculated osmotic pressure of the serum at this time was $20.2 \mathrm{~mm}$. mercury. Three and one-half months later, a reading subsequent to the last one recorded on the chart, the serum protein was 6.6 grams per $100 \mathrm{cc}$. blood and the osmotic pressure $27.2 \mathrm{~mm}$. mercury. Increase of weight on the control diet was coincident with increasing edema. Decline in weight following administration of vitamin $B_{1}$ occurred with rapid loss of edema. The gain of ure 6B). Volume index at this time was 1.14 , color index 1.10. During therapy with vitamin $B_{1}$ there was an increase in hemoglobin, erythrocytes and cell volume, but no significant change in volume or color indexes. At the end of 3 months of vitamin $B_{1}$ and yeast therapy the erythrocytes had increased in number by 34 per cent, the volume index was 0.89 and the color index 0.90 . Pulse rate, systolic and diastolic pressures were taken under the standard conditions of exercise used with Case 1 (see Figure 7). The most striking result was a fall in resting pulse rate. Systolic and diastolic pressures increased slightly at the same time that the pulse rate decreased. The tongue remained smooth and red throughout administration of vitamin $B_{1}$. One week following the addition of yeast, regeneration of papillae was evident and at the end of two weeks the tongue was entirely normal in appearance. Flu- 
oroscopic examination of the gastro-intestinal tract during the control period showed the same marked, irregular filling defect of the stomach noted in 1924 and believed to be due to gastric polyposis. The stomach was hypertonic; peri- implication is clear that definite changes in either the absorption or utilization of food-stuff must have taken place. The fact that serum protein increased during vitamin therapy although the protein intake remained constant may be attrib-

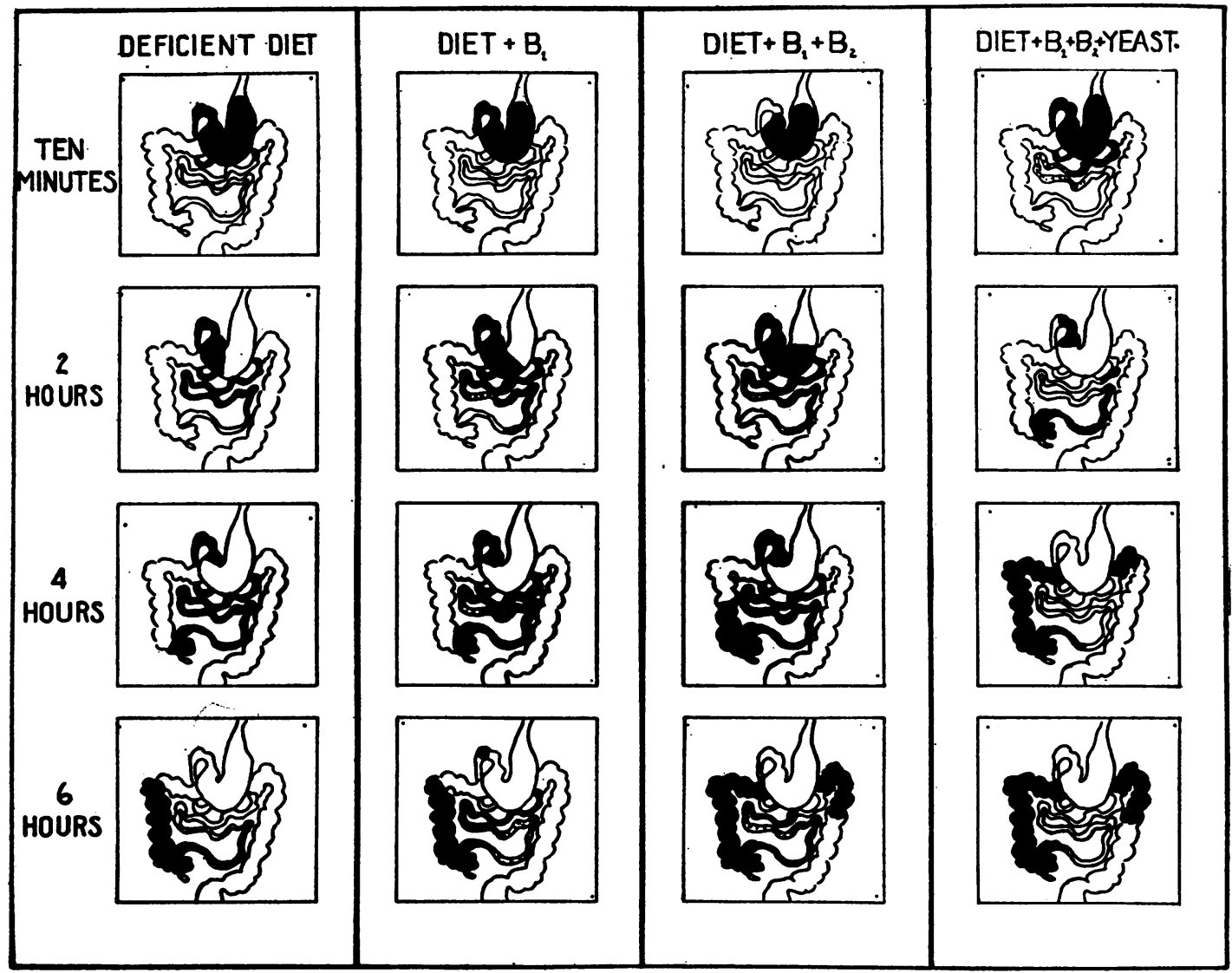

Fig. 5. Case 1. Diagrammatic Representation of Roentgen Appearance of the Gastro-intestinal Tract During the Different Experimental Periods, 10 Minutes, 2, 4 and 6 Hours After a Barium Meal.

stalsis was active and produced deep segmentation. The stomach emptied quickly and the opaque medium progressed very rapidly through both small and large intestines. There was no visible change in gastro-intestinal tone or motility after 3 months on combined vitamin therapy.

\section{DISCUSSION}

The observed increase in weight, one of the most striking results of vitamin therapy, deserves comment. It occurred, associated with positive nitrogen balance, on a constant diet and in the face of loss of edema fluid from the body. The uted to various factors, namely, to increased absorption of protein, increased regeneration of body protein or to redistribution of body water.

It is uniformly found in deficiency experiments in animals that when separate vitamin B fractions are added to the basal diet there occurs a temporary increment in weight which is not maintained until all necessary factors are included in the diet. Similar temporary increase of weight on addition of vitamins $B_{1}$ and $B_{2}$ was observed in Case 1; but this increase was not maintained until yeast therapy had been begun. Evidence was thus provided that additional factors such as are neces- 
sary in animals for maximal gain of weight were likewise required by this patient. That these factors were also necessary for complete relief of symptoms was shown when, upon addition of yeast, symptoms disappeared which had returned toward the end of the period with vitamin $B_{1}$ and $\mathrm{B}_{2}$ combined. Gastro-intestinal symptoms were relieved only after the addition of yeast and it was likewise only at this time that gastro-intestinal tone and motility returned to normal.

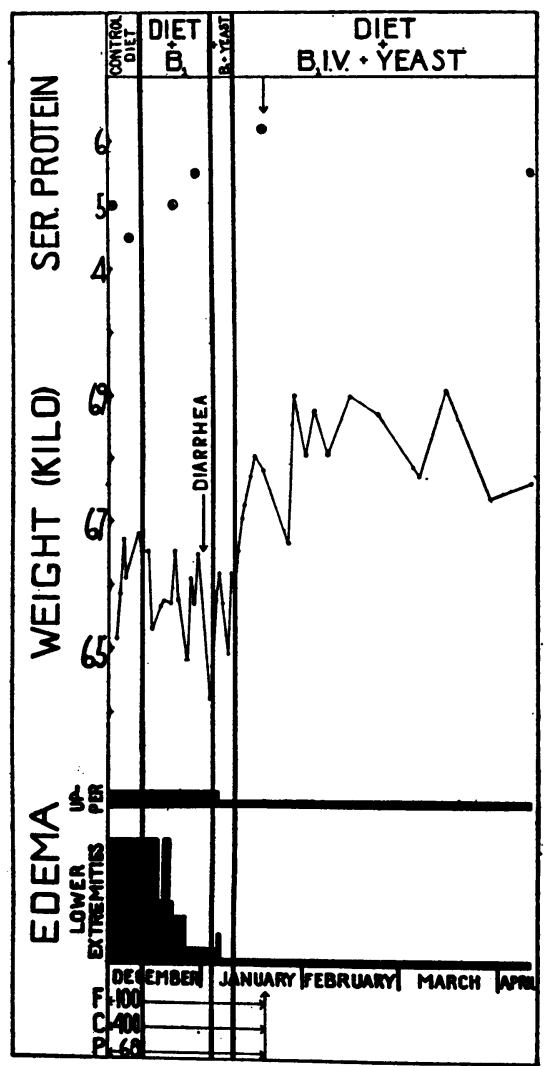

A explanation of the edema exists. After vitamin therapy both patients became free from edema. No apparent reason for this is provided by our studies. In Case 1, the serum protein had been consistently above the concentration thought to represent the critical level. In Case 2, the edema disappeared before there occurred what is regarded as significant alteration in serum protein concentration. The permeability of the capillary wall to protein measured by an indirect method

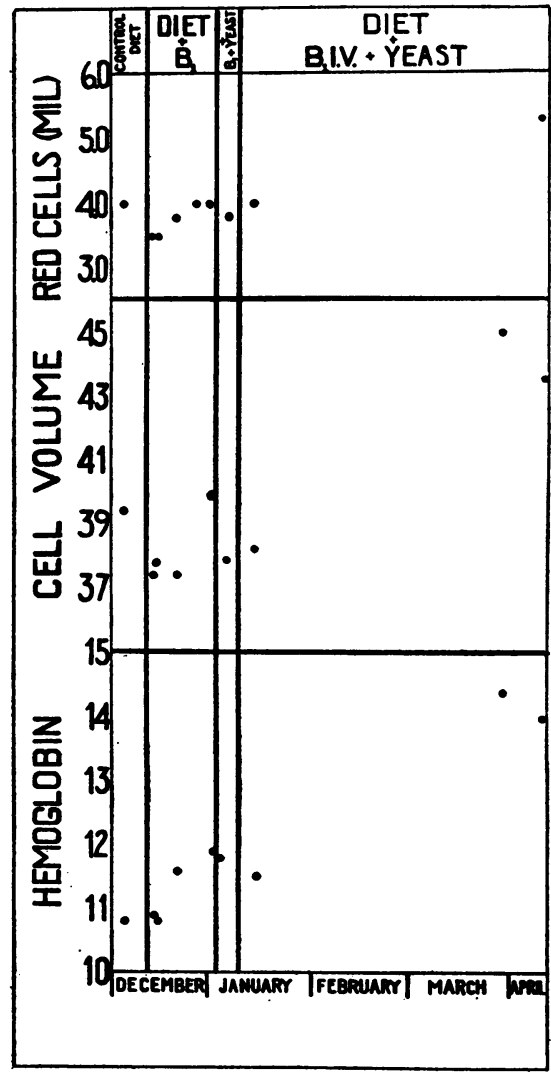

B

FIg. 6. CASE 2.

A. Alterations in Edema, Weight and Serum Protein on Vitamin B Deficient Diet, and Following Administration of Vitamin B Fractions.

Daily intake in grams of protein, carbohydrate and fat is recorded at the bottom of the chart. The arrow at the top of the chart indicates the time at which the patient left the hospital.

\section{B. Alterations in Hemoglobin, Cell Volume and Number of Red Blood Cells.}

It is of interest that both of the patients studied had definite edema. In Case 2 a ready explanation is at hand in the reduced concentration of serum protein. In Case 1 , however, no obvious was not increased in Case 1. Protein estimation carried out on edema fluid obtained from Case 2 yielded a figure of 0.31 gram per $100 \mathrm{cc}$. which indicates that here likewise the capillary wall was 
not abnormally permeable to protein. It seems extremely unlikely that the observed abnormalities in the cardiovascular system during deficiency, viz., reduction in systolic and diastolic pressures and tachycardia could have been responsible for the edema in the absence of signs of cardiac decompensation and in the presence of normal venous pressure. The fact that capillary pressure is usually 2 to $3 \mathrm{~cm}$. water above venous pressure (13) permits the assumption that in these patients capillary pressure was not significantly altered and hence that increased filtration pressure was not responsible for the edema. An unusual capacity of the tissues to bind sodium chloride and water has been postulated in cases of "wet" beriberi (14). Whether such an abnormality existed in

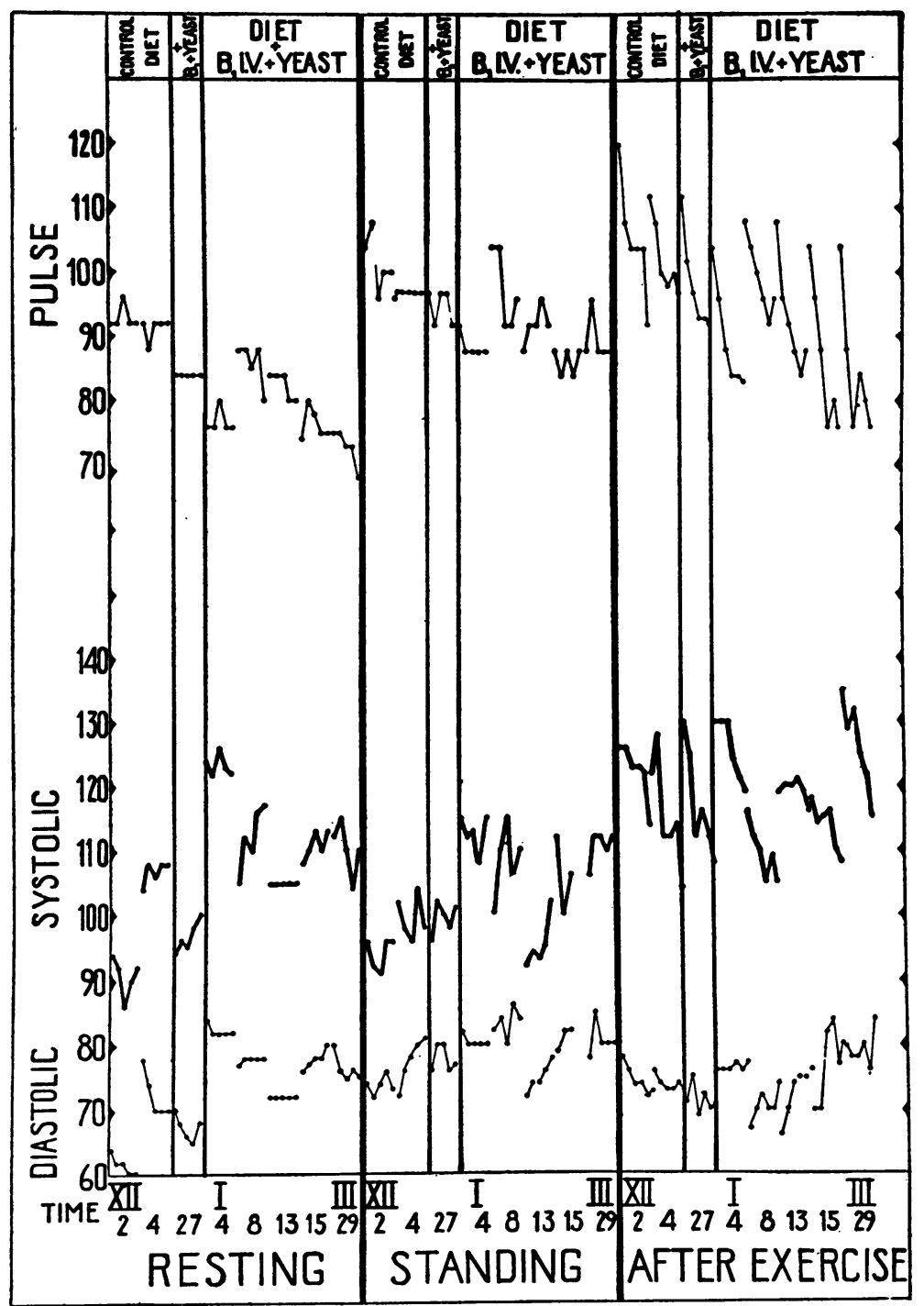

Fig. 7. Case 2. Pulse, Systolic and Diastolic Blood Pressure, at Rest, After Assuming a Standing Position, and After Rapid Ascent up 54 Steps While on the Vitamin B Deficient Diet and During the Administration of Vitamin B Fractions.

Each point in a continuous line represents successive readings at $1 \mathrm{~min}$ ute intervals for 5 minutes. An additional reading was made at the end of 10 minutes after exercise. 
Case 1 was tested by administering $900 \mathrm{cc}$. of normal saline solution by mouth and observing the duration of the resultant gain in weight. Such measurements were made both at the height of the edema and at completion of vitamin therapy. Three days were required in both periods for elimination of the fluid. Applicability of this hypothesis to the present situation therefore seems unlikely.

The relationship of vitamin B to anemia is not clear. Strauss and Castle (15) have suggested that some member of the vitamin B complex, after interaction with normal gastric juice may be the active food factor in prevention of pernicious anemia. They and others (16) (17) (18) have obtained remissions using various yeast extracts, autolyzed yeast preparations, egg white and other vitamin B substances. It is still uncertain, however, which vitamin B fraction is the active factor in these responses. Anemia is rarely seen in beriberi (19), and its occurrence is variable in pellagra. There is little evidence that anemia results from complete vitamin B deficiency in rats (20). Recently, however, Rhoads (21) induced a macrocytic anemia in dogs following prolonged restriction of vitamin $B_{2}$. In the present investigation both patients were moderately anemic while in the deficient state. In Case 1 the anemia was of the microcytic type. Following vitamin therapy there was a slow regeneration of hemoglobin and red cells. Anemia in Case 2 was more striking. A tendency toward macrocytosis was observed at the end of the deficient state. At the conclusion of combined vitamin $B_{1}$ and yeast therapy this tendency had disappeared. Thus in an individual, Case 1, whose gastro-intestinal function was normal, induced vitamin B deficiency of 6 months duration failed to produce significant anemia. In Case 2, however, who suffered impairment in gastro-intestinal function, vitamin B deficiency was associated with anemia of macrocytic type, which improved following vitamin therapy. It is noteworthy that signs and symptoms of neurological involvement indistinguishable from those of early Addisonian anemia developed in Case 1 during the period of deficient diet and disappeared during vitamin administration. Similar signs were present in Case 2 on admission and likewise showed regression on vitamin therapy.

The fact that disturbances of gastro-intestinal tone and motility in Case 1 developed during deficiency and disappeared after therapy justifies the conclusion that they are properly attributable to lack of vitamin B. In Case 2, pre-existing gastro-intestinal disease makes difficult the interpretation of effects of vitamin deficiency on the gastro-intestinal tract. There is ample evidence both in animal experiments and in clinical observations of beriberi and pellagra that severe vitamin B deficiency produces disturbances in gastrointestinal function. Loss of papillae from the tongue (21) and loss of gastric tone while on vitamin B deficient diets (22) have been reported in dogs, as has been delayed gastro-intestinal motility in rats (23).

A sparing action of fat on vitamin $B$ in rats has been demonstrated by Evans and Lepkovsky (24). Conversely, exaggeration of the neuromuscular manifestations of deficient dogs placed on a high carbohydrate diet was reported by Funk (25). In the light of these observations it is interesting that in Case 1, while on a deficient diet, a short period of high fat intake was accompanied by some improvement in symptoms and diminution in edema. When the carbohydrate content of the diet was increased and the fat reduced the improvement ceased.

\section{SUMMARY}

A patient, who received daily for 5 months a constant quantity of an experimental diet adequate except for moderate limitation of vitamin B, developed signs of deficiency. Clinical signs and laboratory evidence of altered function which developed during deficiency disappeared following addition to the diet of especially prepared vitamin $B$ fractions.

A second patient developed spontaneously similar signs of deficiency which were relieved by similar vitamin B therapy.

The outstanding changes accompanying deficiency were: the appearance of definite symptoms, loss of weight, development of edema, fall in blood pressure, loss of gastro-intestinal tone and motility, signs of neurological involvement and in one patient also an increase in pulse rate and a macrocytic type of anemia.

Vitamin fractions contained in yeast were necessary in addition to preparations of vitamin $B_{1}$ 
and $B_{2}$ for complete relief from the changes which accompanied deficiency.

The controlled observations made upon these two individuals indicate that recognizable clinical signs may develop in otherwise normal persons when the vitamin B content of the diet is only moderately limited. This clinical evidence of deficiency is accompanied by alterations in function, corresponding in many respects to changes described in vitamin B deficient animals.

I wish to acknowledge the kindness of Dr. George Cowgill in calculating the vitamin $\mathrm{B}_{1}$ content of the experimental diet and in the advice given by him at the outset of this investigation.

I am indebted also to Dr. F. W. Sunderman for the serum protein analyses, to Dr. L. Jonas for the determinations of respiratory quotient, and to Dr. P. H. Shiffer for his assistance in the fluoroscopic examinations of the gastro-intestinal tract.

\section{BIBLIOGRAPHY}

1. Light, A. B., and Torrance, E. G., Opium addiction. III. The circulation and respiration of human addicts during the administration of morphine. Arch. Int. Med., 1929, 43, 556.

2. Stadie, W. C., A method for the determination of methemoglobin in blood. J. Biol. Chem., 1920, 41, 237.

3. Krogh, A., Turner, A. H., and Landis, E. M., A celluloid capsule for measuring venous pressures. J. Clin. Invest., 1932, 11, 357.

4. Landis, E. M., Jonas, L., Angevine, M., and Erb, W., The passage of fluid and protein through the human capillary wall during venous congestion. $\mathrm{J}$. Clin. Invest., 1932, 11, 717.

5. Bourquin, A., and Sherman, H. C., Quantitative determination of vitamin $G\left(B_{2}\right)$. J. Am. Chem. Soc., 1931, 53, 3501.

6. Chase, E. F., and Sherman, H. C., A quantitative study of the determination of the antineuritic vitamin B. J. Am. Chem. Soc., 1931, 53, 3506.

7. Chick, H., Copping, A. M., and Roscoe, M. H., Egg white as a source of the antidermatitis vitamin $B_{2}$. Biochem. J., 1930, 24, 1748.

8. Osborne, T. B., and Wakeman, A. J., Extraction and concentration of the water-soluble vitamine from brewer's yeast. J. Biol. Chem., 1919, 40, 383.

9. Fouts, P. J., Kempf, C. F., Greene, J. A., and Zerfas,
L. G., Vitamin B intravenously for the treatment of neurologic changes in pernicious anaemia. $J$. Indiana M. A., 1932, 25, 448.

10. Elsom, K. O'S., Clinical manifestations of vitamin B deficiency in adults. Penna. M. J., 1933, 37, 87.

11. Govaerts, P., Influence du rapport albumines globulines sur la pression osmotique des protéines du sérum. Compt. rend. Soc. de biol., 1925, 93, 441.

12. Govaerts, P., Quotient albumines-globulines et pression osmotique des protéines du sérum. Compt. rend. Soc. de biol., 1926, 95, 724.

13. Krogh, A., The Anatomy and Physiology of the Capillaries. Yale University Press, New Haven, 1929.

14. Kobayashi, Y., On the consistency and sodium chloride contents of the blood and edematous fluid in beriberi and other edematous diseases. Progress in Med., 1923, 12, No. 11. Abstracted in Jap. Med. World, 1924, 4, 13.

15. Strauss, M. B., and Castle, W. B., The nature of the extrinsic factor of the deficiency state in primary pernicious anaemia and in related macrocytic anaemias. New England J. Med., 1932, 207, 55.

16. Ungley, C. C., The effect of yeast and wheat embryo in anaemias. I. Marmite, yestamin, and bemax in megalocytic and nutritional hypochromic anaemias. Quart. J. Med., 1933, 2, 381.

17. Wills, L., and Naish, A., A case of pernicious anaemia treated with vitamin $B_{2}$ from egg white. Lancet, 1933, 1, 1286.

18. Wills, L., The nature of the haemopoietic factor in marmite. Lancet, 1933, 1, 1283.

19. Vedder, E. B., Beriberi. Wood, New York, 1913.

20. Cartland, G. F., and Koch, F. C., Diet proteins and vitamins as related to hemoglobin production in the rat. Am. J. Physiol., 1928, 87, 249.

21. Rhoads, C. P., and Miller, D. K., The production in dogs of chronic black tongue with anaemia. J. Exper. Med., 1933, 58, 585.

22. Cowgill, G. R., Deuel, H. J., Jr., Plummer, N., and Messer, F. C., Studies on the physiology of vitamins. IV. Vitamin B in relation to gastric motility. Am. J. Physiol., 1926, 77, 389.

23. Gross, L., The effects of vitamin deficient diets on rats, with special reference to the motor functions of the intestinal tract in vivo and in vitro. J. Path. and Bact., 1924, 27, 27.

24. Evans, H. M., and Lepkovsky, S., Sparing action of fat on the antineuritic vitamin B. J. Biol. Chem., 1929, 83, 269.

25. Funk, C., Studien über Beriberi. XI. Die Rolle der Vitamine beim Kohlenhydrat-stoff wechsel. Ztschr. f. physiol. Chem., 1914, 89, 378. 